\title{
O sertão e a geografia
}

\author{
[ Sertão and geography
}

\section{André Heráclio do Rêgo}

RESUMO - Os sertões foram conquistados e ocupados aos poucos, com base em um conhecimento dividido entre mito e realidade. Criou-se assim uma "geografia imaginária" sobre os sertões dos dois lados do Atlântico, que começou a ser superada com mais vigor no século XVIII. Até então, o interior do continente constituía um extenso vazio cartográfico que, a partir daí, começou a ser preenchido. Esse preenchimento somente foi possível, a exemplo do que ocorreu com a própria expansão pelos sertões, por uma estreita interpendência entre as ações da Coroa e as dos particulares. - PALAVRASCHAVE - sertão; expansão territorial; geografia imaginária • ABSTRACT • The sertões (backlands, hinterland) were conquered and occupied slowly, in a process characterized by the tension between myth and reality, which generated what we can designate as an "imaginary geography" in both sides of the Atlantic Ocean. This kind of geography, which lasted until the I8th Century, is marked by a cartographic vacuum in what refers to the backlands. This vacuum began to be fulfilled at that time, in a process that was made possible by the cooperation between Portuguese authorities and the sertanistas, as it was the case with territorial expansion itself. · KEYWORDS • sertão; territorial expansion; imaginary geography

Recebido em 27 de janeiro de 2016

Aprovado em 27 de janeiro de 2016

DOI: http://dx.doi.org/Io.II6o6/issn.23I6-90IX.voi63p42-66

I Diplomata e historiador. 


\section{A geOgRAFIA IMAgINÁRIA}

A expansão portuguesa pelos territórios de além-mar foi marcada pelo que se pode considerar uma "visão maravilhosa", na qual a imaginação popular fazia "a sua propaganda em prol dos sertões, criando contos fantásticos, propalando visões maravilhosas"2.

Contavam-se coisas estupendas. Interpretavam-se as escassas e obscuras indicações ministradas pelos índios como dados positivos e reais; e com isso davam passo à crendice de uma população, aliás para isso predisposta. Ouvindo-se essas narrativas fabulosas, dir-se-ia que os tesouros do sertão estavam à mercê de quem quer que fosse que com alguma audácia se deliberasse a patentear tão decantadas maravilhas33.

Os mapas daquele tempo pautavam-se dessa forma por uma geografia imaginária caracterizada por um vocabulário bárbaro que representava os habitantes e as maravilhas daqueles sertões, com a descrição dos seus costumes e hábitos. E não se esqueça que, muitas vezes, a própria realidade das coisas deixava muito aquém os sonhos imaginosos dos mais arrojados aventureiros. Assim,

[...] os grandes tesouros do sertão guardavam-se por montanhas altíssimas, por caudais imensos e invadeáveis, por tribos ferozes e por monstros de terrificante aspecto. Nem jamais à imaginação dos homens apareceram tesouros que não fossem defendidos por monstruosidades horrendas 4 .

Nessa perspectiva, o termo "sertão" foi adquirindo conotações ambíguas e complementares, que refletiam uma determinada relação entre a percepção do espaço e a formação do imaginário sobre o interior desconhecido. É justamente nesse

2 SAMPAIO, Teodoro. O sertão antes da conquista (século XVII). Revista do Instituto Histórico e Geográfico de São Paulo. São Paulo: Tipografia do Diário Oficial, I90I, vol. V - I899-I900, p. 79-94, p. 8I.

3 Idem, p. 8I-82.

4 Idem, p. 89-90. 
contexto que se situa o mito da Ilha Brasil, estudado em suas distintas vertentes por Jaime Cortesão e por Sérgio Buarque de Holanda, e que faz parte relevante da geografia imaginária dos sertões. Para Jaime Cortesão, esse conceito, pelo qual o Brasil formaria uma ilha, separada da América Hispânica pelos rios da Prata e Amazonas, unidos por um grande lago, de onde ambos nasciam, seria uma "razão geográfica" de Estado, oposto ao Tratado de Tordesilhas, e que presidiria a formação territorial do Brasil. Ainda para Cortesão, o mito da Ilha Brasil seria a tradução da "consciência perfeita da unidade geográfica, econômica e humana” que caracterizaria o Brasil. Segundo ele, é "na cartografia antiga que deparamos os melhores documentos sobre a evolução e a importância daquele mito na história do Brasil”.

Essa concepção de uma Ilha Brasil rodeada pelo oceano e por dois grandes rios, unidos por um lago, apareceu em cartas como a de Bartolomeu Velho, de I56I, na qual o rio da Prata e o rio Pará, provavelmente o Tocantins de hoje, "ligam-se pela Lagoa Eupana, ao sul da qual se vê o Mar Grande ou Paraguai, que identificamos com o pantanal dos Xarais”. Dessa mesma lagoa partia o rio de São Francisco, “o qual se reúne por um lago menor ao Parnaíba e mais abaixo ao Paraná, que por sua vez se reúne à Lagoa Eupana”.

Nos primeiros mapas de Fernão Vaz Dourado, de I568 e I580, em vez do Pará ou Tocantins, era o Maranhão que se ligava por meio do lago central ao Paraná e ao Uruguai, donde nascia igualmente o São Francisco. No mapa de I580 do mesmo cartógrafo, a Ilha Brasil era representada pela mesma forma, acrescentando-se apenas que o São Francisco e o Maranhão se ligavam também por um lago.

A Ilha Brasil era assim um mito expansionista, em que se antecipava a solução ao problema e ao conflito de soberania, entre Portugal e Castela. Trata-se dessa forma de um mito essencialmente geográfico e político, ao contrário dos mitos castelhanos, heroicos e imaginosos: "o elemento maravilhoso apresenta-se como secundário e importado”. Segundo Cortesão.

[...] nas suas relações com a formação territorial do Estado brasileiro, a ilha humana, que assentava, por sua vez, numa ilha econômica, a da floresta tropical de planície e a de certos produtos agrícolas, como a mandioca e o milho, sobrelevou muito em importância à Ilha Brasil, esquemática e mítica. Desde o século de Quinhentos a Ilha Brasil foi, mais que tudo, uma ilha cultural e, em particular, a ilha da língua geral, que se tornou um vigoroso laço unificante do Estado colonial ${ }^{6}$.

Sérgio Buarque de Holanda, em artigo publicado em I952 e depois reunido na coletânea Tentativas de mitologia, intitulado "Um mito geopolítico: a Ilha Brasil”, antes de criticar a teoria de Cortesão, a resume e sintetiza: tratar-se-ia, segundo ele, da

5 CORTESÃO, Jaime. História do Brasil nos velhos mapas. Rio de Janeiro: Ministério das Relações Exteriores/ Instituto Rio Branco, I957, t. I, p. 339.

6 Idem, p. 339 e seguintes. Especialmente p. 346, 354 e 356.

7 HOLANDA, Sérgio Buarque de. Um mito geopolítico: a Ilha Brasil. In: Tentativas de mitologia. São Paulo: Perspectiva, I979, p. 6I-84. 
[...] ideia de que os portugueses, aspirando, desde o começo da colonização, e antes dela, a ampliar seus domínios neste continente, se apoiaram inicialmente numa espécie de "mito", forjado por parte dos navegadores e cartógrafos, e evoluíram, aos poucos, com o socorro às vezes deliberado dos bandeirantes e da diplomacia lusa, até à visão clara e fecunda de Alexandre de Gusmão ${ }^{8}$.

Como óbice a essa teoria, Holanda apresenta a tendência lusitana a uma colonização litorânea, mais uma necessidade imperiosa que uma vontade precisa, inclusive para evitar o despovoamento da marinha e a sua consequente conquista por eventuais invasores. Nesse sentido, mesmo a conquista de parte do sertão, no caso o amazônico, "podia apresentar-se como simples prolongamento da colonização litorânea, já que as margens do rio mar estendiam para o interior as do mar Oceano".

Sérgio Buarque, por outro lado, integra a Ilha Brasil de Jaime Cortesão em uma "espécie de intencionalismo na história da conquista do sertão", comparável àquele existente no próprio descobrimento do Brasil. Ter-se-iam criado, assim, fronteiras naturais para o território luso nas Américas, que se estenderia não só do Amazonas ao Prata, "como se ampliava sertão adentro, rumo aos limites pressentidos, que a natureza marcou com dois braços de água saindo de um lago chamado de Eupana ou Dourado"ז

Esse mito geográfico e político, entretanto, não seria capaz, por si só, de inspirar, direta ou indiretamente, toda a expansão territorial da América Portuguesa. Sérgio Buarque de Holanda, em síntese, não estava convencido que as entradas e bandeiras fossem tão eficazes quanto as contingências econômicas nesse processo ${ }^{\text {II }}$.

Anos mais tarde, voltaria a escrever sobre a Ilha Brasil, em seu magistral Visão do paraíso, mas desta feita sob um enfoque nitidamente mitológico. Referia-se ele na ocasião ao arquipélago ao qual São Brandão haveria chegado, verdadeiro paraíso onde não havia nem calor, nem frio, nem tristeza, nem fome, do qual fazia parte a Ilha Brasil ou Braçile (conforme mapa de André Benincasa, de I467), ou Ysola de Braçir, na carta de Pizzigno, de I367. Essa Ilha Brasil, vinculada à lenda de São Brandão, pertencia à tradição céltica e foi objeto de busca até o século XVIII ${ }^{\mathrm{I} 2}$.

Em outro livro, $O$ extremo oeste, Sérgio Buarque de Holanda volta a se referir à Ilha Brasil, desta vez para concordar parcialmente com Jaime Cortesão, já que aquele lago no sertão, do qual saíam dois braços, o Amazonas e o Prata, e que se identificava com o lago Xarais, corresponderia ao Pantanal mato-grossense, de onde sai o rio Paraguai, um dos formadores do Prata. Mas o mais importante, segundo ele, é que a Ilha Brasil constituiria de fato um mito expansionista, que se concretizaria na íntima cooperação entre metrópole e colonos, os quais, com “astúcia maquiavélica, tratariam

8 Idem, p. 74 .

9 Idem, p. 76-78.

Io Idem, p. $74,76,77$ e 78 .

II Idem, p. 84 .

I2 HOLANDA, Sérgio Buarque de. Visão do paraíso: os motivos edênicos no descobrimento e colonização do Brasil. São Paulo: Companhia das Letras, 20Io, p. 258 e 273. 
de preencher, através de sucessivas penetrações, todo o espaço insular definido nos mapas". Uma possível objeção seria a de aparecer a representação também em mapas holandeses, alemães e italianos, mas, para Jaime Cortesão, isso se deveria a que esses mapas estrangeiros teriam por base um protótipo lusitano. E conclui:

Não é difícil imaginar como essa mitologia se presta a deitar água no moinho dos que procuram ver tão-somente na decantada capacidade e astúcia portuguesas as origens da expansão geográfica do Brasil. Ela pode mesmo substituir com vantagem a velha ideia de que ao tino de Alexandre de Gusmão, ministro do Conselho Ultramarino e secretário d'el-rei, se deve o bom êxito aparente de Portugal nas discussões preliminares do Tratado de Madri. Segundo essa ideia, o tratado visaria sobretudo a sancionar a obra dos bandeirantes, paulistas como o próprio Gusmão, que nasceu na vila de Santos ${ }^{\text {I3 }}$.

Nem tanto ao mar, nem tanto à terra, já que de ilhas tratamos. Se Jaime Cortesão padecia às vezes de um excessivo patriotismo intelectual português nas suas interpretações, ao atribuir à onisciência da Coroa, direta ou indiretamente, as iniciativas que conduziram à expansão territorial na América do Sul, Sérgio Buarque de Holanda parece padecer do que ele próprio denomina "um exacerbado orgulho regional" paulista que, "impaciente de qualquer jugo, se afirmou frequentemente contra a vontade, os interesses imediatos e os direitos da própria Coroa" ${ }^{14}$, e de que é representante legítimo a historiografia de São Paulo na Primeira República brasileira, período de glorificação histórica do bandeirismo como forma de propaganda da pujança política, econômica e social dos paulistas.

Parece ser mais razoável ficar-se pelo meio termo entre as duas teorias e afirmar a interdependência entre a ação da Coroa e as ações individuais e particularistas. O poder central, a Coroa, não era capaz de executar, sozinha, a empresa da expansão; o poder local individualista, fosse ele exercido por sertanistas ou fazendeiros, era fragmentado em unidades sem conta, não sendo capaz de garantir por si só a exploração das riquezas descobertas ou produzidas. A solução era o compromisso que, pela tolerância e pelo reconhecimento da interdependência, legitimava as duas partes. A iniciativa das bandeiras, assim, podia pertencer - e nem sempre pertencia - a particulares, que investiam nela seus próprios recursos e os de sua parentela; mas as riquezas extraídas, fossem elas ouro ou escravos, eram exportadas para o reino ou para outros domínios portugueses, e pagavam impostos. A Coroa, por sua vez, incapaz de prover sozinha a essas expedições, dava mercês e reconhecia os descobertos. Observe-se que os descobridores de ouro, a primeira coisa que faziam ao voltar era fazer reconhecer pelas autoridades a prioridade de suas descobertas e que a caça ao negro da terra dependia em muito da decretação da guerra justa. A Coroa, ademais, regalava patentes e títulos a esses descobridores, usando assim de um inteligente pragmatismo, que lhe permitia transformar em seus intermediários e representantes nos sertões remotos, aqueles que poderiam ser seus concorrentes,

I3 HOLANDA, Sérgio Buarque de. O extremo oeste. São Paulo: Brasiliense, I986, p. 93.

I4 HOLANDA, Sérgio Buarque de. Tentativas de mitologia, I979, p. 84. 
já que possuíam o poder político, econômico e militar sobre um determinado espaço. Portugal, dessa forma, dividia para reinar.

O mito da Ilha Brasil é tributário assim de uma geografia imaginária que se caracterizava pela existência de riquezas, ocultas ou aparentes, nos sertões americanos. Caracterizava-se também pela origem legendária dos seus grandes cursos de água, geralmente um grande lago, ele também rico em ouro e outros metais e pedras preciosas. Essa geografia imaginária não fornecia contornos precisos, nem coordenadas geográficas exatas, o que fazia encurtar em muito, por exemplo, as distâncias entre a América Portuguesa e as minas de prata do Peru' ${ }^{15}$. Dessa suposta contiguidade geográfica, que realmente existia, mas que se estendia por uma superfície muito mais ampla do que se imaginava, vinha um dos principais argumentos dos que defendiam a existência de metais preciosos no Brasil: se os havia no Peru, necessariamente os haveria também em terras da colônia lusitana, mormente situadas na mesma latitude - o que explica que as primeiras explorações tenham sido feitas nos sertões da capitania de Porto Seguro. E tanto mais seria assim quanto a probabilidade de haver metais preciosos seria maior a Oriente, já que por essas bandas se localizaria, segundo alguns, o Paraíso Terreal.

No outro lado do Atlântico ocorria fenômeno semelhante: os exploradores portugueses se pautavam por uma geografia imaginária que diminuía consideravelmente as distâncias entre a costa angolana e a contracosta moçambicana, o que sem dúvida foi um dos fatores que retardaram a conclusão da travessia do continente. $\mathrm{O}$ tema das riquezas infindáveis também estava presente nessa geografia. Veja-se o caso do reino de Angola, descrito por Domingos de Abreu e Brito em finais do século XVI como "mui grande, e rico, e são, e abastado, de todo o modo de mantimento", e "pela terra ser fertilíssima em grande abundância, e muito povoada em tanto que se afirma ser a mais povoada do mundo" ${ }^{\text {. } 6}$. E riquezas minerais não faltavam ${ }^{\mathrm{I}}$.

Essas riquezas, como as minas de prata, situar-se-iam algumas delas em umas serranias que atravessavam todo o reino de Angola, e que, segundo informação

I5 Tanto é assim que Tomé de Sousa, em carta ao "el-rei”, de I553, escreve: “Item: pelo Rio da Prata arriba trezentas léguas da boca do Norte e ao Nordeste está uma povoação grande de castelhanos da gente que ali levou dom Pedro de Mendoza a qual está em vinte e cinco graus e um quarto e São Vicente está em vinte e três graus e três quartos foi se agora descobrindo pouco e pouco que esta povoação que se chama a Cidade d'Assunção está muito perto de São Vicente e não devem de passar de cem léguas porque pela altura se vê logo claramente. Parece nos cá a todos que esta povoação está na demarcação de Vossa Alteza e se Castela isto negar mal pode provar que é Maluco seu e se estas palavras parecem a Vossa Alteza de mau esférico e pior cosmógrafo terá Vossa Alteza muita razão que eu não sei nada disto senão desejar que todo o mundo fosse de Vossa Alteza e de vossos herdeiros". Carta de Tomé de Sousa a el-rei com muitas notícias das terras do Brasil. Salvador, $\mathrm{I}^{\circ}$ jun. I553. Gavetas da Torre do Tombo, n. 9.

I6 BRITO, Domingos de Abreu e. Um inquérito à vida administrativa de Angola e do Brasil, em fins do século XVI, segundo o manuscrito existente na Biblioteca Nacional de Lisboa, pelo licenciado Domingos de Abreu e Brito publicação revista e prefaciada por Alfredo de Albuquerque Felner. Coimbra: Imprensa da Universidade, I93I, p. 6. I7 Idem. 
disponível, iriam muito longe pelo sertão ${ }^{18}$. Isso nos remete a outro topos dessa geografia imaginária, dos dois lados do Atlântico: o das serranias enormes e inacessíveis, guardiãs de tesouros incalculáveis. É o caso, por exemplo, de um famoso cordão de serras, na capitania de Tete, Moçambique, cortado por um rio, e onde se viam "penhas altíssimas talhadas a pique de uma parte e de outra com uma ilhota no meio"ז. $\mathrm{Ou}$, ainda em Moçambique, da famosa serra de Morombara, de seis léguas de largura e três de comprido; e cujo cabeço se via "sobre as nuvens e trovoadas, que como golilhas lhe assentam sobre os ombros" ${ }^{20}$.

Da geografia imaginária da África portuguesa faziam parte também os rios de origem misteriosa, geralmente um grande lago nos sertões. Não à toa, Gomes Eanes de Zurara, descrevendo o descobrimento e conquista da Guiné, na África Ocidental, informou que as caravelas portuguesas haviam chegado ao rio Nilo, que devia supostamente estar localizado uns quantos milhares de quilômetros para o Oriente. Isso se explica porque, tratando-se de rio de grandeza maravilhosa, passaria por muitas terras, "contra o ocidente", fazendo "em meio de si uma ilha, que há nome Meroe” ${ }^{\text {II }}$ O próprio Plínio considerava que não havia homem que soubesse certamente das fontes do Nilo rio "que anda mui longa terra por desertos, e por terras tão quentes, que se acenderiam se por ele não fosse" ${ }^{\text {"2 }}$. O rio, após a sua fonte, por não querer correr por cima de terras e areias, nem pelos lugares desertos e maus, se ia "escondido já quantas jornadas", até chegar ao seu curso conhecido. Nada a admirar, pois, que o rio que os portugueses haviam encontrado na Guiné fosse um braço do Nilo. O tema dos rios que correm por vias subterrâneas é mais um topos da geografia imaginária, que remete aos próprios rios que nascem do Paraíso Terreal.

Antônio de Oliveira Cadornega, na sua História geral das guerras angolanas, também deu notícia de alguns desses rios. Um deles, o abundante Lucala, cujas águas vinham se despenhando de tão longe do sertão, a fertilizar tantas terras, em que tinham seu sustento a gente portuguesa "e gentio do grêmio de santa Madre Igreja,

I8 Informação do reino de Angola e das suas minas de prata e sal (Século XVI). In: BRÁSIO, Padre Antônio. Monumenta Missionaria Africana - África Ocidental - Suplemento (sécs. XV, XVI e XVII), coligida e anotada pelo padre Antônio Brásio, C.S.Sp. Vol. XV. Lisboa: Academia Portuguesa de História, I988, p. 368-373, p. 364-365. I9 BARRETO, Padre Manuel. Informação do Estado e conquista dos rios de Cuama vulgar e verdadeiramente chamados Rios de Ouro. Ao conde vice-rei João Nunes da Cunha pelo padre jesuíta Manuel Barreto, II de dezembro de I667. Boletim da Sociedade de Geografia de Lisboa. Lisboa: Imprensa Nacional, I885, $4^{\mathrm{a}}$ série, n. I, p. 33-59, p. 42.

20 Idem, p. 4I.

2I AZURARA, Gomes Eanes de. Crônica do descobrimento e conquista da Guiné, escrita por mandado de el-rei D. Afonso V, sob a direção científica, e segundo as instruções do ilustre Infante D. Henrique, pelo cronista Gomes Eanes de Azurrara, fielmente trabalhada do manuscrito original contemporâneo, que se conserva na Biblioteca Real de Paris, e dada pela primeira vez à luz por diligência do Visconde da Carreira, Enviado Extraordinário, e Ministro Plenipotenciário de S. Majestade Fidelíssima na corte de França, precedida de uma introdução, $e$ ilustrada com algumas notas pelo Visconde Santarém, etc. Paris: J. P. Aillaud, I84I, p. 289 e 290.

22 Idem, p. 29I. 
vassalos todos de Sua Alteza, que Deus guarde"23. Também ele fala de uma lagoa lendária, que estava no íntimo deste sertão e da qual saíam quatro rios caudalosos: o Cuanza, o Cunene, o Hila e Cubo. Ademais destes havia o rio Coango, ou Zaire, como lhe chamavam pelo sertão dentro ${ }^{24}$. Para Cadornega, o rio Cuanza seria o primeiro entre os mais famosos rios que havia no mundo, "pela abundância de suas águas, pela fertilidade de diversas nações e línguas de reinos e tão dilatadas províncias, afora as que não são sabidas, regando suas dilatadas terras, onde se criam diversas castas de animais e diversidade de pescado, com tantas monstruosidades”25. Mencionou também o rio Longa, que teria "seu nascimento na lagoa ou brejo, de que diz algum do gentio sai o Zaire, o Cuanza e o Cunene, e algumas pessoas que discursaram esta matéria têm para si serem braços do Nilo”. Mas, para ele,

[...] o que uma pessoa não andou e viu com os olhos, se não pode falar afirmativamente; o que se diz virem suas águas de uma lagoa do íntimo do sertão, é por alguma notícia que disso deu por maior o gentio da terra dentro, os quais não são escriturários e falam em as matérias conforme a sua barbaridade, que de curiosos não têm nada ${ }^{26}$.

Dos dois lados do Atlântico, os caminhos do sertão, fossem eles terrestres ou fluviais, eram buscados e percorridos por homens que se pautavam por essa geografia imaginária, a qual cada vez mais dava passo a um maior conhecimento empírico do terreno. Nesse processo não faltava a visão estratégica, como no caso do "caminho do Brasil", em terras americanas, e no "caminho da costa à contracosta", em terras de África. O moto e a razão principal, entretanto, eram a busca de riquezas, ou a garantia da sobrevivência. Foi assim que se foi conformando, aos poucos, a expansão territorial e a conquista dos sertões, com sucesso muito maior na América do que na África Portuguesa, em um contexto de interdependência entre a iniciativa oficial e a privada.

\section{O SERTÃo E A CARTOGRAFIA}

Antônio Carlos Robert de Moraes nota, com acerto, "que é no apetite territorial de certas sociedades europeias que devemos buscar o móvel primeiro da expansão marítima", e que é "na capacidade plástica de se apropriar de lugares os mais diversos

23 CADORNEGA, Antônio de Oliveira. História Geral das Guerras Angolanas - I680 - Tomo III. Anotado e corrigido por José Matias Delgado. Lisboa: Agência Geral do Ultramar, I972, p. I33.

24 Idem, p. I59-I60.

25 Idem, p. I60-I6I.

26 Idem, p. I80. 
e moldá-los segundo seus interesses que se pode avaliar o êxito ou fracasso dos vários empreendimentos coloniais" 27 .

É o caso dos portugueses, na América e na África, e da conquista dos sertões. Estes foram conquistados aos poucos, e com base num conhecimento crescente, que sempre se caracterizou pela tensão entre o mito e a realidade. Com efeito, desde a Idade Média relatos como os de Marco Polo, Mandeville e outros se caracterizavam pela mistura entre informações verídicas sobre regiões até então desconhecidas, e fábulas, o que, se encantava o público, contribuía pouco para alargar os conhecimentos geográficos e a representação gráfica de novos espaços.

A exploração da costa africana contribuiu para mudar essa situação, em um processo lento, que se caracterizou por uma tensão constante entre a experiência vivida dos portugueses, o saber livresco medieval e legado clássico, representado sobretudo pela Geographia de Ptolomeu. Essa tensão se refletiu diretamente na cartografia.

O centro principal desse confronto foi, durante algum tempo, o desenho da África. O perfil do litoral foi logo objeto de consenso, prevalecendo as informações reais trazidas pelos portugueses. Mas no que se referia aos sertões africanos, ao desconhecido interior continental, entretanto, a ausência de informações e de contatos diretos obrigou os cartógrafos a recorrer ao conhecimento presente nas obras de Ptolomeu. Não havia, assim, evidência comparável à exploração náutica portuguesa no que se refere àqueles sertões, situação que persistiu até bem avançado o século XIX. Assim, como a cartografia portuguesa era tributária da expansão marítima e a maior parte das cartas tinha caráter náutico, o interior dos continentes era um vazio cartográfico com poucas informações de natureza geográfica: quando muito, rios, panorâmicas de cidades, bandeiras, fauna, flora, nativos, cenas da vida cotidiana e detalhes morfológicos sem muita relação com o terreno (figura I).

27 MORAES, Antonio Carlos Robert. A dimensão territorial nas formações sociais latino-americanas. In: AZEREDO, Francisca L. Nogueira de e MONTEIRO, John Manuel (orgs.). Raízes da América Latina. Rio de Janeiro/ São Paulo: Expressão e Cultura/Edusp, I996, vol. 5, p. I43-I54, p. I43. 


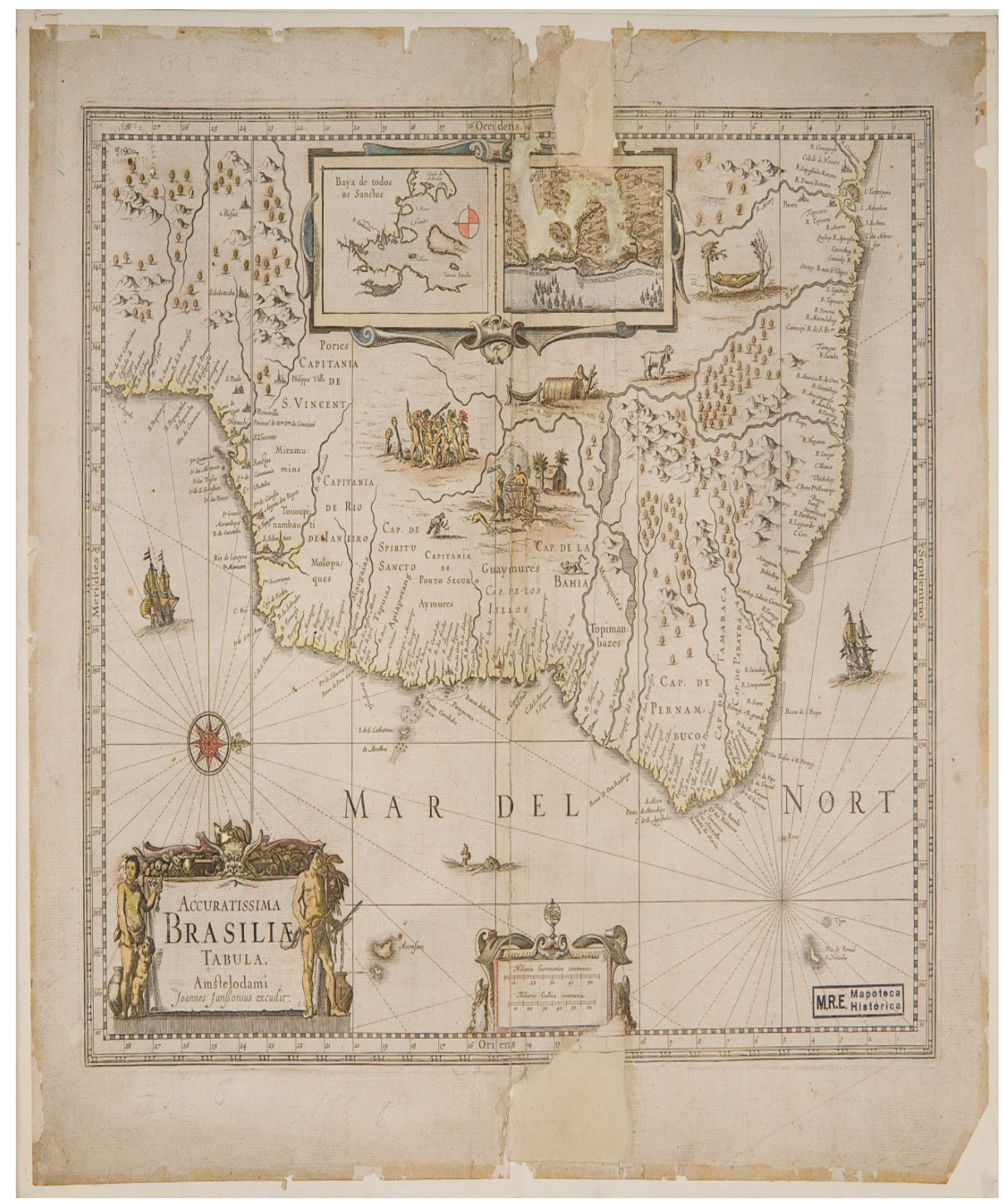

Figura I - Accuratissima Brasília tabula. Joannes Janssonius. [I6- com a descrição do que se supunha haver nos sertões. Exemplo da geografia imaginária, em contraste, quem sabe irônico, com o adjetivo empregado no título ("accuratissima”). Original na Mapoteca do Itamaraty, Rio de Janeiro.

Recorreu-se assim a uma geografia imaginária, que sobredimensionava o tamanho da Abissínia, única parte relativamente conhecida e que foi utilizada para completar os espaços desconhecidos do resto do continente. Dessa geografia imaginária fazia parte também a interpretação ptolomaica sobre a nascente o curso do Nilo. Nela, os sertões africanos eram dominados pelas montanhas da Lua, localizadas abaixo da linha equinocial, e da qual surgiam, rumo norte, vários 
rios que desaguavam em dois grandes lagos paralelos. Cada um desses originava respectivamente um outro rio, que se juntavam depois de passada a linha do Equador para originar o Nilo.

Além do desconhecimento factual puro e simples, as representações cartográficas portuguesas, tais como as de Lázaro Luís e Fernão Vaz Dourado, pagavam tributo à política de sigilo da Coroa, pela qual os portugueses escondiam tanto o que sabiam quanto o que ignoravam. Assim surgiu um crescente barroquismo no desenho da África, cujo objetivo principal era ocultar o desconhecimento geográfico dos sertões continentais. No atlas de Lázaro Luís, por exemplo, o desenho de uma cena pictórica oculta a então desconhecida geografia do deserto do Saara. Outra estratégia para dissimular o desconhecimento geográfico, verificado na Tabula Aphricae nova, do início do século XVII, de Luís Teixeira, era atribuir ao interior do continente uma toponímia fictícia.

No que se refere aos sertões americanos, as imagens começaram a fixar-se com os atlas de Fernão Vaz Dourado de I568, I570 e I57I, em cartas ricamente decoradas e que davam informações cada vez menos imaginosas sobre o interior do continente. Nesse contexto, a representação ganhou mais definição em meados dos anos I580, com a obra atribuída a Luís Teixeira, Roteiro de todos os sinais, na qual o espaço era figurado com maior pormenor em substituição aos mapas que representavam o Brasil como um vago litoral, que avançava para sul e para oeste (figura 2). 


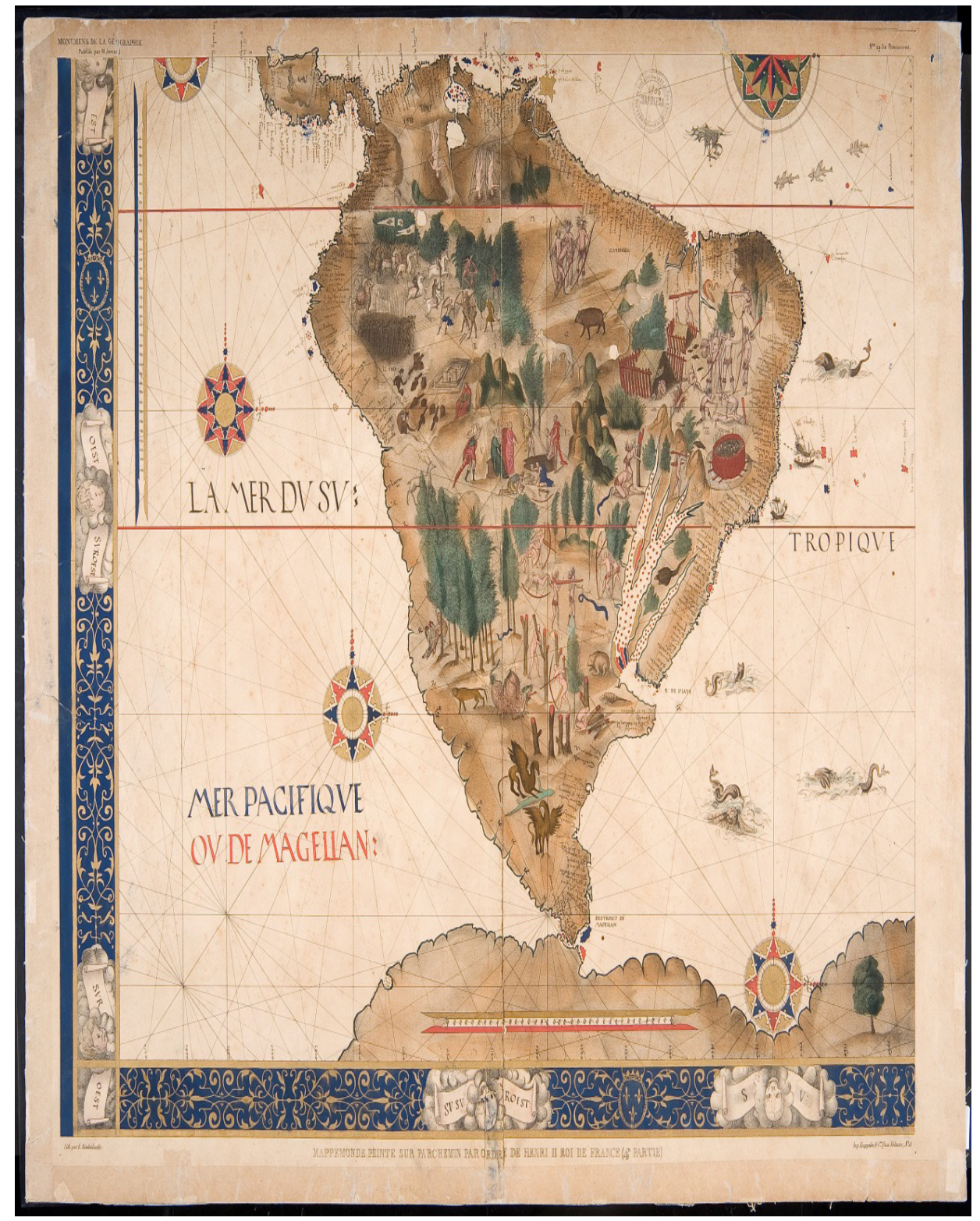

Figura 2 - A América Meridional no mapa-múndi. Pierre Descelliers,

I546. Outro exemplo da geografia imaginária dos sertões americanos.

Original na Mapoteca do Itamaraty, Rio de Janeiro.

No que se refere ao breve interregno do domínio holandês, a cartografia, bem mais rigorosa do que a portuguesa, revela uma colonização limitada à costa e incapaz de avançar para os sertões: 
São raros os mapas holandeses que nos revelam do sertão brasileiro muito mais do que os mapas portugueses anteriores à invasão holandesa. O que não é de admirar, porque o reconhecimento do sertão brasileiro, liderado pelos paulistas, teve lugar essencialmente durante a segunda metade do século XVII e durante o século seguinte. Em todo o caso, nunca até a data do domínio holandês se tinham produzido tantos mapas e de tal qualidade da região do Nordeste brasileiro. Graças aos engenheiros, pintores e cartógrafos trazidos pelos holandeses, fizeram-se centenas de mapas, plantas, pinturas e desenhos, das capitanias controladas pelos holandeses. Merece destaque, entre os cartógrafos holandeses, George Markgraf, que levou a cabo um trabalho minucioso de cartografia das regiões de Pernambuco, Sergipe, Paraíba e Rio Grande. Na verdade, o período correspondente à ocupação holandesa do Nordeste não foi suficientemente longo para permitir um avanço do reconhecimento do interior e da sua colonização. Afinal, convém não esquecer que também o avanço português no interior do Brasil foi o resultado de diferentes esforços que se prolongaram por vários séculos ${ }^{28}$.

Essa geografia imaginária somente começou a ceder passo no século XVIII, quando dom João V decidiu montar observatórios e obter os instrumentos mais modernos, com o apoio de especialistas franceses. Teve especial destaque nessa operação dom Luís da Cunha, embaixador em Paris, que fez contatos com o grande nome da geografia e da cartografia francesa, Jean Baptiste Bourguignon d'Anville. Esse francês elaborou valiosas obras sobre geografia e história, bem como algumas centenas de cartas geográficas, baseadas em excelente documentação. As suas cartas, cingidas tanto quanto possível à realidade observada, permitiram pela primeira vez chegar à conclusão do muito que se ignorava sobre o interior dos grandes continentes, onde assinalavam vastos espaços em branco ${ }^{29}$.

Haveria, nessas representações, uma aparente contradição entre a feição iluminista do mapa e as imagens mitológicas que ele contém. Trata-se de uma cartografia repleta de subjetividade, embora também marcada pela objetividade, assegurada pelo uso das técnicas mais modernas.

Como alertavam os filósofos iluministas, o estudo da natureza com suas formas de representação geográfica da Terra adquiria na época uma dimensão política, fenômeno que encontrava expressão na cartografia daquele tempo. [...] A Carte de l'Amérique Méridionale está imbuída da visão geopolítica que dom Luís da Cunha e D’Anville compartilhavam tanto sobre o império português na América quanto sobre a arte da cartografia enquanto espelho do mundo real. Reflete ainda os mecanismos e critérios de validação científicos do conhecimento geográfico adquirido ${ }^{30}$.

28 ALMEIDA, André Ferrand de. A formação do espaço brasileiro e o projeto do Novo Atlas da América Portuguesa (I7I3-I748). Lisboa: Comissão Nacional para as Comemorações dos Descobrimentos Portugueses, 200I, p. 27.

29 CORTESÃO, Jaime. Op. cit., t. I, p. IO6.

30 FURTADO, Júnia Ferreira. Oráculos da geografia iluminista. Dom Luís da Cunha e Jean-Baptiste Bourguignon D’Anville na construção da cartografia do Brasil. Belo Horizonte: Editora UFMG, 20I2, p. 27. 
Nessa mesma época, Espanha e Portugal se enfrentavam para negociar suas possessões territoriais. Os mapas, vistos como "espelhos do território", constituíam ferramentas fundamentais na hora de negociar os territórios em litígio. Porém, uma das questões que se impunha para que os mapas pudessem desempenhar o papel que lhes devia ser destinado no teatro da diplomacia da América do Sul era o relativo desconhecimento da geografia dos territórios em questão.

Nesse sentido, segundo Jaime Cortesão, na cartografia portuguesa sobre o Brasil haveria preocupações específicas, que chegariam mesmo a configurar um sistema de classificação, segundo essas preocupações. Haveria assim uma incipiente cartografia do pau-brasil, primeira riqueza explorada, uma cartografia do açúcar, menos impressionante que a holandesa, e uma cartografia militar.

Há, por outro lado, uma grande diferença entre a representação geral do território na cartografia do século XVII, em que só o litoral dispunha de um tratamento mais detalhado, e a representação cartográfica mais rigorosa, possibilitada pela existência de instrumentos de precisão astronômica, característica do século XVIII. Donde se conclui haver uma relação entre o progressivo descobrimento do espaço sul-americano e a necessidade crescente, por parte do Estado, de melhorar a sua representação cartográfica de forma a intervir com mais eficácia no território que viria a formar o Brasil ${ }^{35}$.

Os sertanistas deixaram relatos orais ou escritos, roteiros de viagem, verdadeiros mapas mentais, que permitiam aos seus sucessores encontrarem seu caminho sertão adentro. Esses roteiros faziam parte dos testamentos ou foram recolhidos, no século XVIII, da tradição oral. Alguns deles chegaram mesmo a ser analisados por D’Anville por intermédio de dom Luís da Cunha, constituindo assim fontes para a Carte de l'Amérique Méridionale. Os roteiros, relações e mapas consubstanciam uma "necessidade de conhecer e delimitar" os espaços conquistados ou em vias de sê-lo, e, no que se refere ao século XVIII na América portuguesa, constituem um momento de inflexão na cartografia, já que revelam um contínuo desvelar da geografia do interior do Brasil a partir de uma apreensão empírica da mesma, ademais de refletirem as transformações técnicas e conceituais da cartografia da época. Desse modo, o avanço dos portugueses para os sertões além da linha de Tordesilhas resultou na necessidade de conhecer a geografia do interior e de confeccionar mapas considerados mais "precisos".

Assim, durante o século XVIII, os espaços interiores das cartas, antes ocupados por representações pictóricas, foram preenchidos por rios, montanhas, acidentes naturais do terreno, arraiais, vilas, caminhos e roças, impondo-se progressivamente "uma representação do espaço mediada pela matemática e pela geometria, pois se acreditava que, por meio dessas ciências, seria possível fazer da cartografia um espelho perfeito do mundo real"32.

A cartografia portuguesa do Brasil e da África limitou-se, durante muito tempo, praticamente à costa. Somente no reinado de dom João V, com a ajuda de especialistas estrangeiros, os sertões começaram a ser efetivamente representados nos mapas. E

3I ALMEIDA, André Ferrand de. Op. cit., p. 42-45.

32 FURTADO, Júnia Ferreira. Op. cit., p. 26. 
isso se deu em uma época, o século XVIII, em que as rivalidades diplomáticas e as redefinições de fronteiras levaram a uma crescente dependência entre cartografia e diplomacia. A cartografia, nesse sentido, permitiu estudar em detalhe a formação e a consolidação do território e, muitas vezes, não somente descreveu o território, mas o criou, precedendo-033. É o caso dos domínios portugueses, dos dois lados do Atlântico, no século XVIII.

Reitere-se que, anteriormente, os mapas não representavam a contento a vastidão do território e do seu povoamento, dando-se uma ideia apenas da costa do mar, "mas ainda essa, por ser em ponto miúdo, diminutíssima quanto aos precisos lugares da costa por nomes de vilas, e sítios de pouca monta, os quais não costumam pôr-se nas cartas"34 (figura 3). Para mudar tal situação, as autoridades portuguesas começaram a se interessar pela descrição dos sertões. É o caso do governador de Benguela, que tentou recolher informações daqueles que tinham toda a experiência e que haviam investigado a maior parte daquele sertão, para assim ter as luzes necessárias para tomar suas decisões, sem "trovar de repente"35. Ou do barão de Moçamedes, que, se referindo às suas "indagações sertanistas", comentava que, apesar de todos os esforços e diligências feitos, não poderia responder pela sua inteira exação, já que para isso "deveriam vir geógrafos, e tirar-nos da dependência das luzes dos estrangeiros”. Assegurava, no entanto, serem as cartas geográficas resultantes as mais chegadas à verdade, por serem traçadas com base na carta de Bourguignon D’Anville sobre a África Meridional, entre outras fontes impressas, ademais de serem o fruto de "muitas conferências dos Conhecedores da Costa e Práticos do negócio do Sertão, e indagações peculiares, desesperando-me infinito as crassas ignorâncias destes Sertanejos" ${ }^{36}$.

33 Idem, p. 22 e 24.

34 ALMEIDA, André Ferrand de. Op. cit., p. I62-I67.

35 Carta do governador de Benguela Pedro José Correia de Quevedo Magez a Martinho de Mello e Castro, de 4 de maio de I785. In: FELNER, Alfredo de Albuquerque. Angola: Apontamentos sobre a colonização dos planaltos e litoral do sul de Angola. Extraídos de documentos históricos por Alfredo de Albuquerque Felner (obra póstuma). Lisboa: Divisão de Publicações e Biblioteca da Agência Geral das Colônias, I940, t. I, p. 2I6-220, p. 220.

36 Copiador reservado do barão de Mossamedes. In: FELNER, Alfredo de Albuquerque. Op. cit., t. I, p. 22 I. 


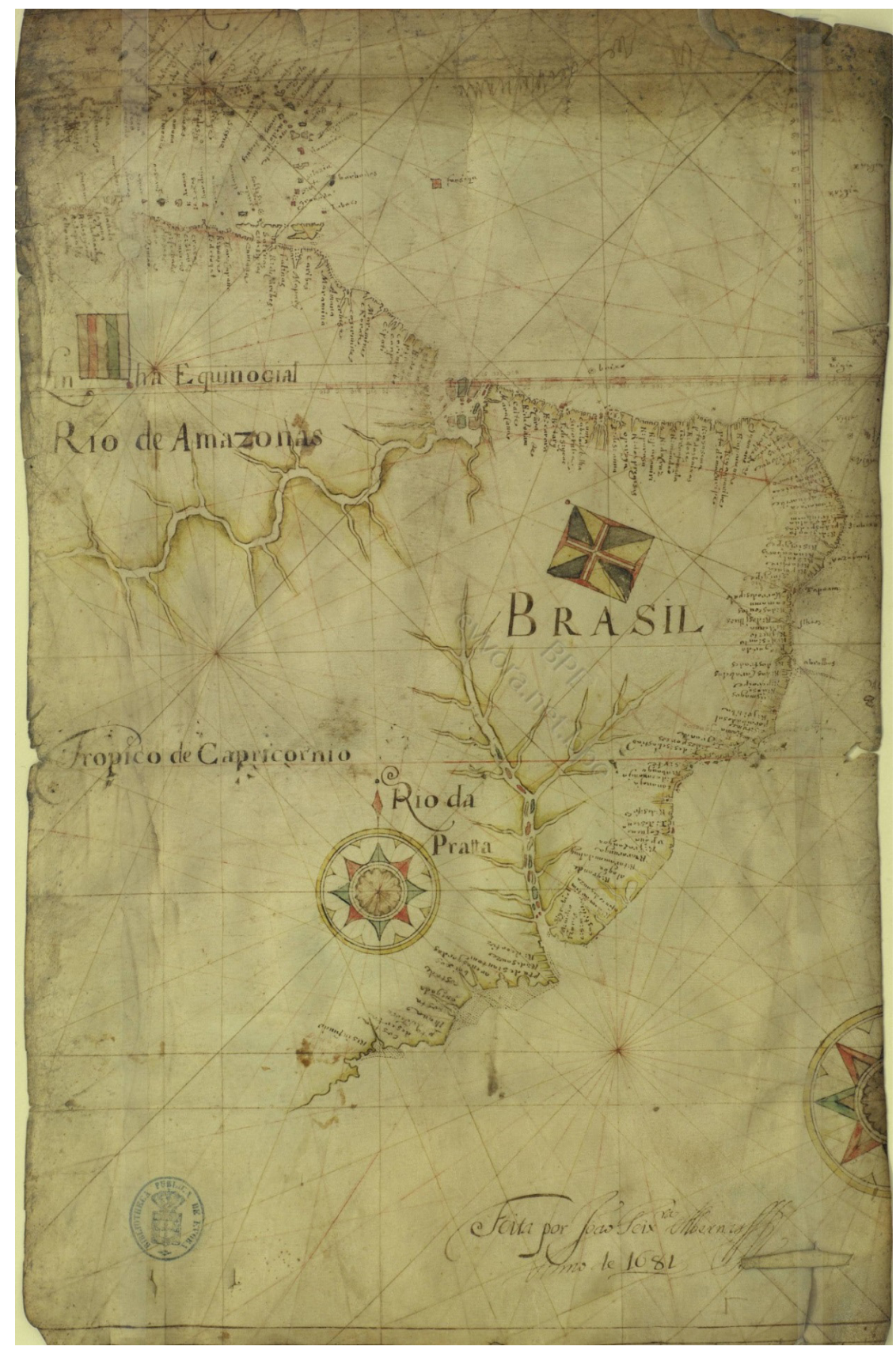

Figura 3 - Carta atlântica, de João Teixeira de Albernaz II (I68I). O sertão do Brasil aparece como um vazio, delimitado pelo rio da Prata e pelo rio Amazonas. Original na Biblioteca Pública de Évora. 
Desde o século XVIII, portanto, no caso brasileiro, sertão e litoral passaram a ser o padrão das descrições do espaço nacional. O Brasil era uma fonte de espaços vazios intermináveis, mesmo considerando que o sertão, pelo menos no período colonial, fosse menos um espaço geográfico que um espaço socioeconômico e essencialmente simbólico, como na bela imagem de Capistrano de Abreu sobre os sertões de dentro e os sertões de fora. No caso da África, essa geografia do sertão foi desenvolvida sobretudo pelas tentativas de travessia do continente.

O conceito de sertão passou a ser, nesse contexto, muito utilizado na cartografia, mais como qualificativo de lugar que como um local específico. Trata-se da indicação de lugares pouco ocupados, ou seja, usar a designação de sertão indicaria a ideia subjacente de ocupar aquele espaço e, em consequência, levar a civilização até ali. Sertão é, assim, um qualificativo de espaço, que pode ter componentes etnográficos como denominação "sertão dos tapuias"37. É um qualificativo que indica também uma espécie de fronteira, que separa a civilização da barbárie e, nesse sentido, indica a necessidade de atravessar, conquistar e incorporar as regiões assim qualificadas ${ }^{38}$ (figura 4).

37 WOOD, A. J. R. Russell. Centers and Peripheries in the Luso-Brazilian World, I500-I808. In: DANIELS, Christine e KENNEDY, Michael V. Negotiated empires: Centers and peripheries e in the Americas, I500-I820. Nova York/Londres: Routledge, 2002, p. I05-I42, p. I23.

38 MALHEIROS, Márcia. "Homens da fronteira". Índios e capuchinhos na ocupação dos Sertões do Leste, do Paraíba ou Goytacazes. Séculos XVIII e XIX. Tese (Doutorado). Niterói: Universidade Federal Fluminense, 2008, p. 36. 


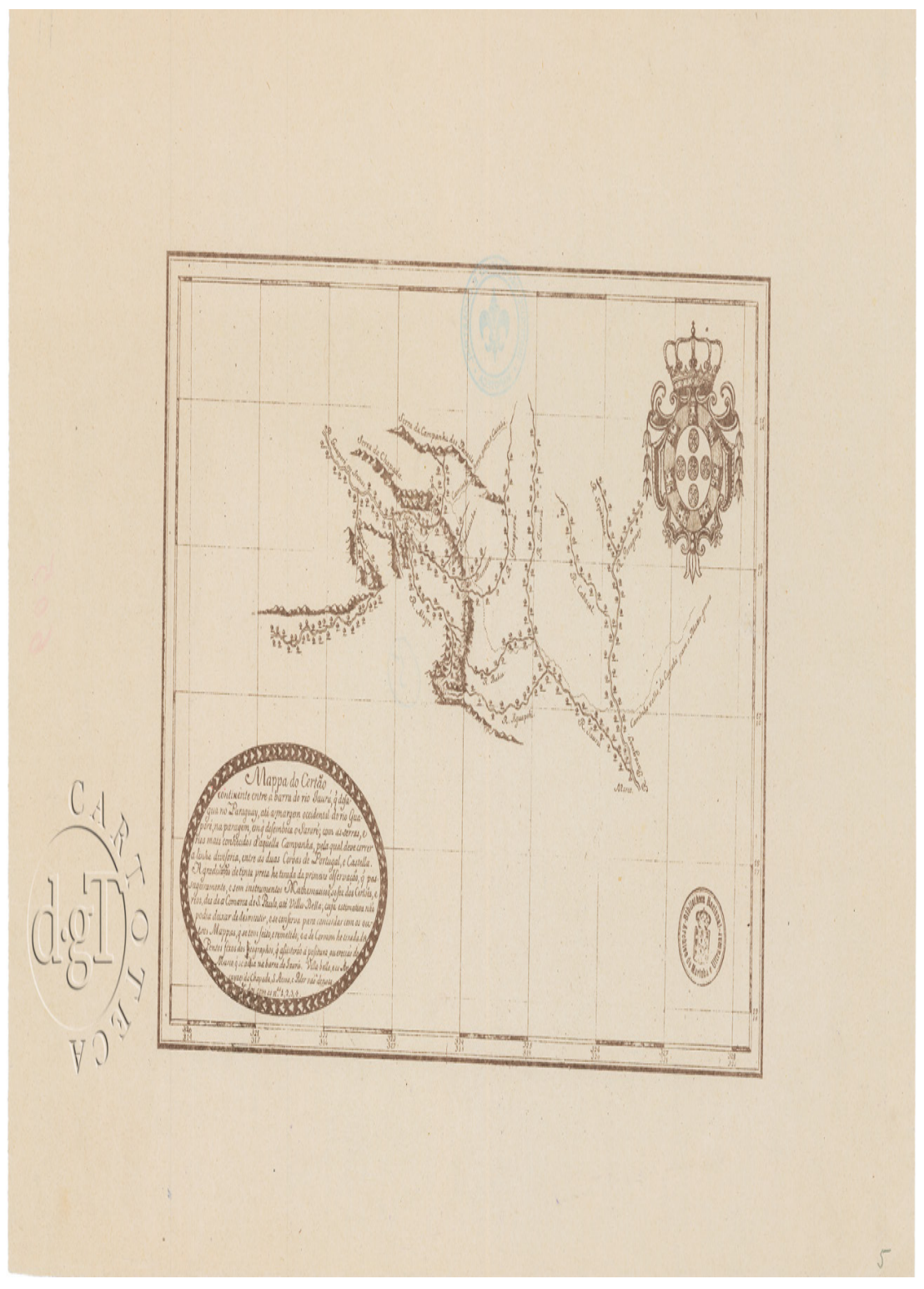

Figura 4- Um dos inúmeros "mapas do sertão", acompanhado de um qualificativo. Produzido no decorrer do processo de conquista e ocupação das terras interiores do Brasil. Fonte: Trata-se de um ozalide, com brasão real e carimbo da Biblioteca Nacional-Arquivo da Marinha e Ultramar. Tem como legenda: Mappa do Certão, continente entre a barra do rio Iaurú, q. desagua no Paraguay, até a margem ocidental do rio Guaporé, na ma paragem, em que desemboca o Sararé; com as serras, e rios mais conhecidos d'aquella Campanha, pela qual deve correr a linha divisória, entre as duas Coroas de Portugal e Castela. A graduação de tinta preta é tirada da primeira observação, q. passageiramente. e sem instrumentos Matemáticos, se fez dos Certões, e rios, desde a Comarca de S. Paulo, até Villa-Bella; cuja 
estimativa não podia deixar de desmentir, e se conserva para concordar com os outros Mapas, q. se tem feito, e remetido; e a de Carmim é tirada dos Pontos fixos dos Geógrafos, q. assistirão á postura, ou erecção do Marco, q. se acha na barra do Iaurú. Villa-bella, e os Arraiais da Chapada, S. Ana, e Pilar vão denotados com os nº I,2,3, 4. COTA: 4IAp5-4 IGP.

Do ponto de vista estritamente topográfico, pelo menos até o século XVIII, é um denotativo de imprecisão: "centro do sertão", "interior do sertão”, "sertão de cima”, "sertão de baixo”. No século XVIII, a precisão topográfica aumentou com o maior conhecimento do território, e com ela, a precisão do qualificativo: "sertão do rio São Francisco", que tomava por referência o rio do mesmo nome. Com base nessa referência, surgiram as expressões "sertões de dentro" e "sertões de fora", para designar os sertões da Bahia e de Pernambuco, divididos pelo rio.

Outro qualificativo de sertão era o adjetivo “deserto", o que seria, em alguma medida, uma reiteração do conceito, sobretudo do ponto de vista populacional. Outro qualificativo, 'vastíssimo', presente sobretudo no século XVI, começou a ter sua abrangência reduzida, em função também do maior conhecimento do terreno. No Plano Geográfico de uma parte do Rio Negro da Villa de Barcellos, até a Serra de Cucui: e da boca do Rio Uaupés the primeira Cachoeira, "levantado" por ordem de João Pereira Caldas, Governador e Capitão General nomeado das Capitanias de Mato Grosso, e Cuiabá e Comissário Geral das Demarcações de Limites da parte do Norte, e feito por Francisco José de Lacerda, de I78I, por exemplo, fica patente a oposição entre sertões povoados e sertões desertos. Nele, a leste do rio Parnaíba, vem a nota "distritos da capitania do Piauí muito povoado todo ele quase em geral”; a oeste do rio Itapicuru, entretanto, vem a observação: "matos gerais, sertões despovoados, entregues à discrição do gentilismo”. Entre as cabeceiras do rio das Balsas e do Parnaíba, por outro lado, vem descrito: “destes pontos para cá é sertão grande e deserto, vão confinar com Minas Gerais”. Já na margem esquerda do Tocantins: "sertão imenso desconhecido que se não sabe ao menos por indícios aonde vai ter nem os rios que em si contém"39.

Em outros mapas, os cartógrafos se referiam à "incertidão do interior destes sertões"40 e reconheciam, muitas vezes, que o "mais interior não se sabe ainda que muito confusamente”, como reconhecia, neste último caso, Francisco Tosi Colombina ${ }^{4}$.

Assim, desde meados do século XVII, os sertões começaram a ter um tratamento geográfico mais preciso, reduzindo-se a imprecisão e a vaguidade reinantes até então. Essa tendência continuaria no século XVIII, passando o sertão a referir-se a determinado campo, a determinada vila, a determinada cidade. Deve-se observar, entretanto, que por muito tempo essa maior precisão de alguns sertões ainda

39 ADONIAS, Isa. Mapas e planos manuscritos relativos ao Brasil Colonial conservados no Ministério das Relações Exteriores e descritos por Isa Adonias para as comemorações do Quinto Centenário da morte do Infante dom Henrique. Volume I - Texto. Rio de Janeiro: Ministério das Relações Exteriores/Serviço de Documentação, I960, p. 245 .

40 CORTESÃO, Jaime. Op. cit., t. II.

4I ADONIAS, Isa. Op. cit., p. 265. 
conviveria com o caráter impreciso de outros tantos. Mais do que nunca, havia sertões e sertões. "Sertões bem distantes" conviviam com o sertão de algumas vilas... O emprego da palavra "sertão" foi, desse modo, afetado pela longa duração e pelas cambiantes realidades geográficas, sociais, históricas e econômicas que retratava. Esses sertões foram sendo cartografados, aos poucos, por leigos, missionários, funcionários reais, sertanistas, engenheiros (figura 5).

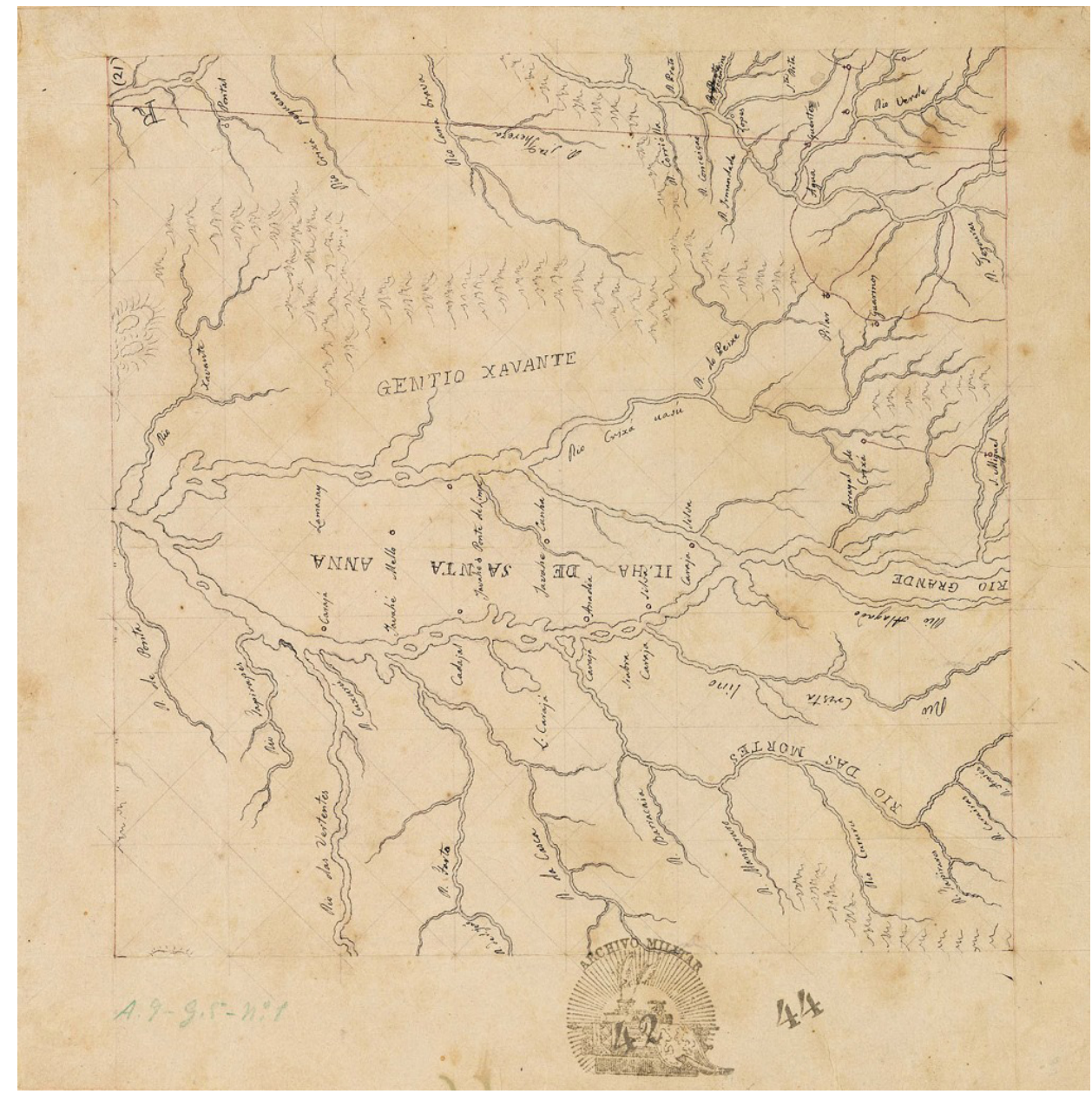

Figura 5 - Mapa manuscrito dos sertões centrais do Brasil. Original no Gabinete de Estudos de Engenharia Militar, em Lisboa.

Esses mapas, em sua maior parte manuscritos, que se encontravam anexados a vários documentos - relatórios de governadores, cartas de embaixadores ou de missionários, planos de generais, projetos de arquitetos, diários de exploradores etc. -, serviram muitas vezes como fontes, na elaboração de cartas estrangeiras impressas, 
como acontecia desde o século XVI (figura 6) ${ }^{42}$. Havia muitos erros cartográficos, já que o trabalho não era realizado por especialistas, situação que começou a mudar com a missão dos padres matemáticos. Outra dificuldade era a política de sigilo adotada pela Coroa portuguesa. As cartas e os roteiros sobre o sertão, se existiam antes do século XVIII, eram de difícil acesso, já que el-rei não queria facilitar aos inimigos o conhecimento das riquezas do sertão.

42 GARCIA, João Carlos. Nos contrafortes dos Andes: reflexões geográficas sobre a cartografia do Brasil setecentista. Mercator, ano 3, n. 6, p. I9-24, 2004. 


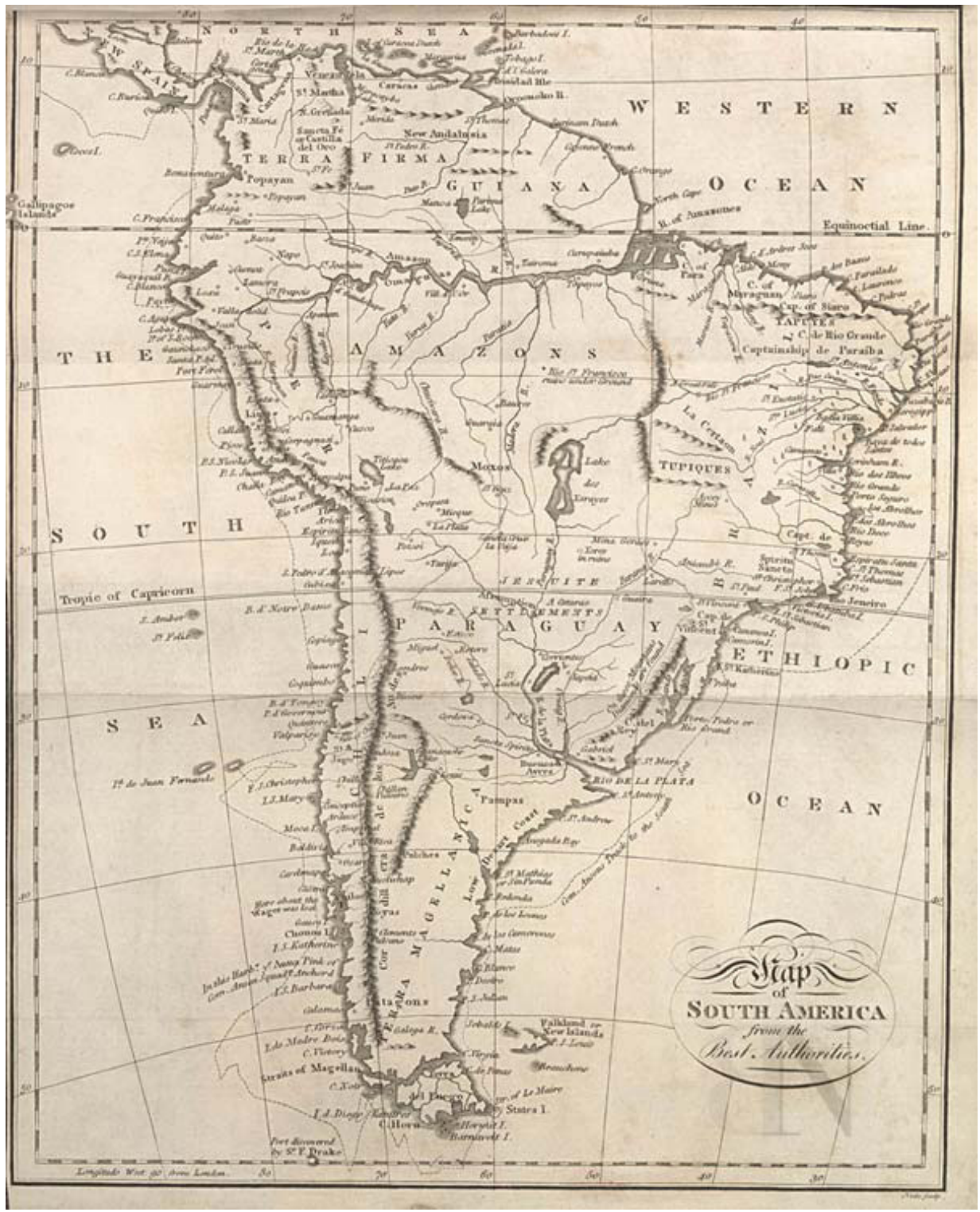

Figura 6 - Neste mapa está presente a indicação "la certam” nos sertões da Bahia, Minas Gerais e Goiás. Fonte: Map of South America from the Best Authorities / Neele sculp. - Escala [ca. I:34 000000 entre S I0 ${ }^{\circ}$ S 30]. - I mapa : água-forte, p\&b ; 24,8xI9,5 cm em folha de 25,6x20,3 cm. Biblioteca Nacional de Portugal. 


\title{
CONCLUSÃo
}

Os sertões foram conquistados e ocupados aos poucos, com base em um conhecimento dividido entre mito e realidade. Havia uma tensão permanente entre a experiência vivida dos portugueses, o saber livresco medieval, sobretudo de origem bíblica, e o legado clássico, representado principalmente por Ptolomeu. Criou-se assim uma "geografia imaginária" sobre os sertões dos dois lados do Atlântico, que começou a ser superada com mais vigor no século XVIII, caracterizado, ele próprio, por negociações territoriais que definiram as fronteiras da América do Sul. Até então, o interior do continente constituía um extenso vazio cartográfico que, a partir daí, começou a ser preenchido.

Esse preenchimento somente foi possível, a exemplo do que ocorreu com a própria expansão pelos sertões, por uma estreita interpendência entre as ações da Coroa e as dos particulares. Assim, da mesma forma que as autoridades portuguesas e os sertanistas dependiam uns dos outros para transformar em realidade a expansão territorial, havia uma cooperação, em alguns casos involuntária, entre sertanistas, diplomatas e cartógrafos na confecção de uma cartografia mais precisa dos sertões. Os primeiros eram os autores de roteiros, itinerários e mapas primitivos, alguns dos quais recolhidos pelas autoridades portuguesas, serviram como fontes para os mapas de especialistas como Bourguignon D'Anville, cartógrafo d'el Rei de França. Os diplomatas, de que é exemplo paradigmático dom Luís da Cunha, eram os intermediários entre sertanistas e cartógrafos na circulação desse material e, sobretudo, eram os principais responsáveis pela utilização desses mapas nas negociações territoriais.

\section{SOBRE O AUTOR}

\begin{abstract}
ANDRÉ HERÁCLIO DO RÊGO é diplomata e historiador. Doutor em Estudos Portugueses, Brasileiros e da África Lusófona pela Universidade de Paris Nanterre - título revalidado pela USP como de doutor em História Social. Atualmente, pós-doutorando do IEB.
\end{abstract}




\section{REFERÊNCIAS BIBLIOGRÁFICAS}

ADONIAS, Isa. Mapas e Planos Manuscritos relativos ao Brasil Colonial conservados no Ministério das Relações Exteriores e descritos por Isa Adonias para as comemorações do Quinto Centenário da morte do Infante dom Henrique. Volume I-Texto. Rio de Janeiro: Ministério das Relações Exteriores/Serviço de Documentação, I960.

ALMEIDA, André Ferrand de. A formação do espaço brasileiro e o projeto do Novo Atlas da América Portuguesa (I7I3-I748). Lisboa: Comissão Nacional para as Comemorações dos Descobrimentos Portugueses, 200I.

AZURARA, Gomes Eanes de. Crônica do descobrimento e conquista da Guiné, escrita por mandado de el-rei D. Afonso V, sob a direção científica, e segundo as instruções do ilustre Infante D. Henrique, pelo cronista Gomes Eanes de Azurrara, fielmente trabalhada do manuscrito original contemporâneo, que se conserva na Biblioteca Real de Paris, e dada pela primeira vez à luz por diligência do Visconde da Carreira, Enviado Extraordinário, e Ministro Plenipotenciário de S. Majestade Fidelíssima na corte de França, precedida de uma introdução, e ilustrada com algumas notas pelo Visconde Santarém, etc. Paris: J. P. Aillaud, I84I.

BARRETO, Padre Manuel. Informação do Estado e conquista dos rios de Cuama vulgar e verdadeiramente chamados Rios de Ouro. Ao conde vice-rei João Nunes da Cunha pelo padre jesuíta Manuel Barreto, II de dezembro de I667. Boletim da Sociedade de Geografia de Lisboa. Lisboa: Imprensa Nacional, I885, $4^{\text {a }}$ série, n. I, p. 33-59.

BRITO, Domingos de Abreu e. Um inquérito à vida administrativa de Angola e do Brasil, em fins do século XVI, segundo o manuscrito existente na Biblioteca Nacional de Lisboa, pelo licenciado Domingos de Abreu e Brito, publicação revista e prefaciada por Alfredo de Albuquerque Felner. Coimbra: Imprensa da Universidade, I93I.

CADORNEGA, Antônio de Oliveira. História Geral das Guerras Angolanas - I680 - Tomo III. Anotado e corrigido por José Matias Delgado. Lisboa: Agência Geral do Ultramar, I972.

CARTA de Tomé de Sousa a el-rei com muitas notícias das terras do Brasil. Salvador, $\mathrm{I}^{\circ}$ jun. I553 $_{5}$-Gavetas da Torre do Tombo, n. 9. 4509. XVIII, 8-8.

CARTA do governador de Benguela Pedro José Correia de Quevedo Magez a Martinho de Mello e Castro, de 4 de maio de I785. In: FELNER, Alfredo de Albuquerque. Angola - Apontamentos sobre a colonização dos planaltos e litoral do sul de Angola. Extraídos de documentos históricos por Alfredo de Albuquerque Felner (obra póstuma). Lisboa: Divisão de Publicações e Biblioteca da Agência Geral das Colônias, I940, t. I.

COPIADOR reservado do barão de Mossamedes. In: FELNER, Alfredo de Albuquerque. Angola - Apontamentos sobre a colonização dos planaltos e litoral do sul de Angola. Extraídos de documentos históricos por Alfredo de Albuquerque Felner (obra póstuma). Lisboa: Divisão de Publicações e Biblioteca da Agência Geral das Colônias, I940, t. I.

CORTESÃO, Jaime. História do Brasil nos velhos mapas. Rio de Janeiro: Ministério das Relações Exteriores/ Instituto Rio Branco, I957, t. I e II.

DELVAUX, Marcelo Motta. As minas imaginárias: O maravilhoso geográfico nas representações sobre o sertão da América Portuguesa - séculos XVI a XIX. Dissertação (Mestrado). Belo Horizonte: Universidade Federal de Minas Gerais, 2009.

FURTADO, Júnia Ferreira. Oráculos da geografia iluminista. Dom Luís da Cunha e Jean-Baptiste Bourguignon D’Anville na construção da cartografia do Brasil. Belo Horizonte: Editora UFMG, $20 I 2$. 
GARCIA, João Carlos. Nos contrafortes dos Andes: reflexões geográficas sobre a cartografia do Brasil setecentista. Mercator, ano 3, n. 6, 2004.

HOLANDA, Sérgio Buarque de. Um mito geopolítico: a Ilha Brasil. In: Tentativas de mitologia. São Paulo: Perspectiva, I979.

. O extremo oeste. São Paulo: Brasiliense, I986.

. Visão do paraíso: os motivos edênicos no descobrimento e colonização do Brasil. São Paulo: Companhia das Letras, 2010.

INFORMAÇÃO do reino de Angola e das suas minas de prata e sal (Século XVI). In: BRÁSIO, Padre Antônio. Monumenta Missionaria Africana - África Ocidental - Suplemento (sécs. XV, XVI e XVII), coligida e anotada pelo padre Antônio Brásio, C.S.Sp. Vol. XV. Lisboa: Academia Portuguesa de História, I988.

MALHEIROS, Márcia. "Homens da fronteira”. Índios e capuchinhos na ocupação dos Sertões do Leste, do Paraíba ou Goytacazes. Séculos XVIII e XIX. Tese (Doutorado). Niterói: Universidade Federal Fluminense, 2008.

MORAES, Antonio Carlos Robert. A dimensão territorial nas formações sociais latino-americanas. In: AZEREDO, Francisca L. Nogueira de e MONTEIRO, John Manuel (orgs.). Raízes da América Latina. Rio de Janeiro/São Paulo: Expressão e Cultura/Edusp, I996, vol. 5.

RELAÇÃO de Gago e Tumbuctu (I590). In: BRÁSIO, Padre Antônio. Monumenta Missionaria Africana África Ocidental - Segunda Série (I685-I699), coligida e anotada pelo padre Antônio Brásio, C.S.Sp. Suplemento aos séculos XV, XVI, XVII. Volume VII. Lisboa: Centro de Estudos Africanos da Faculdade de Letras da Universidade de Lisboa, 2004.

RESENDE, Garcia de. Descoberta do reino do Congo (I482). In: BRÁSIO, Padre Antônio. Monumenta Missionaria Africana - África Ocidental - Segunda Série (I47I-I53I), coligida e anotada pelo padre Antônio Brásio, C.S.Sp. vol. I. Lisboa: Agência Geral do Ultramar, I952.

SAMPAIO, Teodoro. O sertão antes da conquista (século XVII). Revista do Instituto Histórico e Geográfico de São Paulo, volume V - I899-I900. São Paulo: Tipografia do Diário Oficial, I90I.

WOOD, A. J. R. Russell. Centers and Peripheries in the Luso-Brazilian World, I500-I808. In: DANIELS, Christine e KENNEDY, Michael V. Negotiated Empires - Centers and Peripheries $e$ in the Americas, I500-I820. Nova York/Londres: Routledge, 2002. 